\title{
Mediterranean diets and metabolic syndrome status in the PREDIMED randomized trial
}

\author{
Nancy Babio BSc PhD, Estefanía Toledo MD PhD, Ramón Estruch MD PhD, Emilio Ros MD PhD, \\ Miguel A. Martínez-González MD PhD, Olga Castañer MD PhD, Mònica Bulló BSc PhD, \\ Dolores Corella DPharm PhD, Fernando Arós MD PhD, Enrique Gómez-Gracia MD PhD, \\ Valentina Ruiz-Gutiérrez PhD, Miquel Fiol MD PhD, José Lapetra MD PhD, \\ Rosa M. Lamuela-Raventos DPharm PhD, Lluís Serra-Majem MD PhD, Xavier Pintó MD PhD, \\ Josep Basora MD, José V. Sorlí MD PhD, Jordi Salas-Salvadó MD PhD; for the PREDIMED Study Investigators*
}

\begin{abstract}
Background: Little evidence exists on the effect of an energy-unrestricted healthy diet on metabolic syndrome. We evaluated the long-term effect of Mediterranean diets ad libitum on the incidence or reversion of metabolic syndrome.
\end{abstract}

Methods: We performed a secondary analysis of the PREDIMED trial - a multicentre, randomized trial done between October 2003 and December 2010 that involved men and women (age 55-80 yr) at high risk for cardiovascular disease. Participants were randomly assigned to 1 of 3 dietary interventions: a Mediterranean diet supplemented with extravirgin olive oil, a Mediterranean diet supplemented with nuts or advice on following a low-fat diet (the control group). The interventions did not include increased physical activity or weight loss as a goal. We analyzed available data from 5801 participants. We determined the effect of diet on incidence and reversion of metabolic syndrome using Cox regression analysis to calculate hazard ratios (HRs) and $95 \%$ confidence intervals (Cls).

Results: Over 4.8 years of follow-up, metabolic syndrome developed in $960(50.0 \%)$ of the 1919 participants who did not have the condition at baseline. The risk of developing meta- bolic syndrome did not differ between participants assigned to the control diet and those assigned to either of the Mediterranean diets (control v. olive oil HR 1.10, 95\% Cl 0.94-1.30, p $=0.231$; control v. nuts HR $1.08,95 \% \mathrm{Cl} 0.92$ $1.27, p=0.3)$. Reversion occurred in $958(28.2 \%)$ of the 3392 participants who had metabolic syndrome at baseline. Compared with the control group, participants on either Mediterranean diet were more likely to undergo reversion (control v. olive oil HR 1.35, 95\% Cl 1.15-1.58, $p<0.001$; control v. nuts HR $1.28,95 \% \mathrm{Cl} 1.08-1.51$, $p<0.001)$. Participants in the group receiving olive oil supplementation showed significant decreases in both central obesity and high fasting glucose $(p=0.02)$; participants in the group supplemented with nuts showed a significant decrease in central obesity.

Interpretation: A Mediterranean diet supplemented with either extra virgin olive oil or nuts is not associated with the onset of metabolic syndrome, but such diets are more likely to cause reversion of the condition. An energy-unrestricted Mediterranean diet may be useful in reducing the risks of central obesity and hyperglycemia in people at high risk of cardiovascular disease. Trial registration: ClinicalTrials.gov, no. ISRCTN35739639.
Competing interests: See end of article.

This article has been peer reviewed.

*The complete list of PREDIMED Study

Investigators appears at the end of the article.

Correspondence to: Jordi Salas-Salvadó, jordi.salas@urv.cat

CMAJ 2014. DOI:10.1503 /cmaj.140764
$\mathrm{M}$ etabolic syndrome is a cluster of 3 or more related cardiometabolic risk factors: central obesity (determined by waist circumference), hypertension, hypertriglyceridemia, low plasma high-density lipoprotein (HDL) cholesterol levels and hyperglycemia. Having the syndrome increases a person's risk for type 2 diabetes and cardiovascular disease..$^{1,2}$ In addition, the condition is associated with increased morbidity and allcause mortality. ${ }^{1,3-5}$ The worldwide prevalence of metabolic syndrome in adults approaches
$25 \%{ }^{6-8}$ and increases with age ${ }^{7}$ especially among women, ${ }^{8,9}$ making it an important public health issue.

Several studies have shown that lifestyle modifications, ${ }^{10}$ such as increased physical activity, ${ }^{11}$ adherence to a healthy diet ${ }^{12,13}$ or weight loss, ${ }^{14-16}$ are associated with reversion of the metabolic syndrome and its components. However, little information exists as to whether changes in the overall dietary pattern without weight loss might also be effective in preventing and managing the condition. 
The Mediterranean diet is recognized as one of the healthiest dietary patterns. It has shown benefits in patients with cardiovascular disease $^{17,18}$ and in the prevention and treatment of related conditions, such as diabetes, ${ }^{19-21}$ hypertension $^{22,23}$ and metabolic syndrome. ${ }^{24}$

Several cross-sectional ${ }^{25-29}$ and prospective $^{30-32}$ epidemiologic studies have suggested an inverse association between adherence to the Mediterranean diet and the prevalence or incidence of metabolic syndrome. Evidence from clinical trials has shown that an energy-restricted Mediterranean $\operatorname{diet}^{33}$ or adopting a Mediterranean diet after weight $\operatorname{loss}^{34}$ has a beneficial effect on metabolic syndrome. However, these studies did not determine whether the effect could be attributed to the weight loss or to the diets themselves.

Seminal data from the PREDIMED (PREvención con DIeta MEDiterránea) study suggested that adherence to a Mediterranean diet supplemented with nuts reversed metabolic syndrome more so than advice to follow a low-fat diet..$^{35}$ However, the report was based on data from only 1224 participants followed for 1 year. We have analyzed the data from the final PREDIMED cohort after a median follow-up of 4.8 years to determine the long-term effects of a Mediterranean diet on metabolic syndrome.

\section{Methods}

\section{Study design and population}

The PREDIMED study was a large, parallelgroup, multicentre, randomized, controlled field trial designed to assess the effects of the Mediterranean diet on the primary prevention of cardiovascular disease (www.predimed.es).

The protocol, design and methods of the trial have been described elsewhere. ${ }^{17,36}$ Briefly, community-dwelling men (aged 55-80 yr) and women (aged 60-80 yr) with no previously documented cardiovascular disease were recruited for the study and were eligible to participate if they had either type 2 diabetes or at least 3 cardiovascular risk factors: hypertension, high plasma low-density lipoprotein (LDL) cholesterol, low plasma HDL cholesterol, overweight or obesity, current history of smoking and family history of premature coronary artery disease. From October 2003 to June 2009, 7447 participants were randomly assigned to 1 of 3 nutrition interventions $(1: 1: 1)$. Two groups were advised to follow a Mediterranean diet supplemented with either extra-virgin olive oil $(n=2543)$ or nuts ( $n=2454)$, and 1 group (the control group) was advised to follow a low-fat diet $(n=2450)$. The institutional review board of the hospital clinic in Barcelona, Spain, accredited by the United States Department of Health and Human Services Update for Federal Wide Assurance for the Protection of Human Subjects for International (non-US) Institutions approved the study protocol on July 16, 2002. The institutional review boards of the individual recruitment centres also approved the study protocol, and participants gave their informed consent.

To evaluate the effect of the dietary interventions on metabolic syndrome status, we analyzed data from those participants for whom biochemical determinations were available at baseline and for at least 2 years of follow-up. We performed two separate analyses: the first on the incidence of metabolic syndrome in participants who did not have the condition at baseline, and the second on reversion of metabolic syndrome in participants who had the condition at baseline.

\section{Interventions}

Personalized advice was given to participants in both Mediterranean diet groups to increase their adherence to the intervention. Participants in both Mediterranean diet groups received either extravirgin olive oil (about $1 \mathrm{~L} / \mathrm{wk}$ ) or mixed nuts $(30 \mathrm{~g} / \mathrm{d} ; 15 \mathrm{~g}$ walnuts, $7.5 \mathrm{~g}$ hazelnuts and $7.5 \mathrm{~g}$ almonds) at no cost; participants in the control group received small nonfood gifts. The nutrient composition of the olive oil and nuts used in the study was assessed. ${ }^{17}$ Participants were not advised on calorie restriction, and physical activity was not promoted for any intervention group.

At baseline and quarterly thereafter, dietitians gave individual and group training sessions to provide information on typical Mediterranean foods, seasonal shopping lists, meal plans and recipes. Participants assigned to the control diet received recommendations to reduce their intake of all types of fat, from both animal and vegetable sources. Before October 2006, participants in the control group had only received a leaflet describing the low-fat diet. Thereafter, they received personalized advice and were invited to group sessions held with the same frequency as in the Mediterranean groups. During each training session, participants in the Mediterranean diet groups completed a 14-item questionnaire ${ }^{37}$ to assess adherence to the intervention; participants in the control group completed a 9-item dietary screener to assess compliance with the low-fat diet.

\section{Outcomes}

Our primary outcome was metabolic syndrome status, which was defined in the PREDIMED study in accordance to the updated harmonized International Diabetes Federation and the Ameri- 
can Heart Association/National Heart, Lung, and Blood Institute criteria. ${ }^{38} \mathrm{We}$ calculated the proportion of participants who did not meet criteria at baseline, but who had at least 3 components of metabolic syndrome yearly thereafter (i.e., incident metabolic syndrome). In addition, we calculated the proportion of participants who met criteria at baseline, but who had fewer than 3 components yearly thereafter (i.e., reversion of metabolic syndrome). We considered only the first change in status (incidence or reversion) in our analyses.

\section{Measurements}

At baseline and yearly for a median follow-up of 4.8 years, all of the participants were given personal interviews during which they com- pleted the following items: a questionnaire about lifestyle variables, medical history and medication use; a 14-item validated questionnaire ${ }^{37}$ designed to assess adherence to the Mediterranean diet; a validated 137-item semiquantitative food-frequency questionnaire ${ }^{39}$ and the validated Spanish version ${ }^{40}$ of the Minnesota leisure-time physical activity questionnaire. In addition, trained staff determined anthropometric variables and blood pressure. Blood samples were collected from all participants after an overnight fast. We measured fasting plasma glucose, total cholesterol, HDL cholesterol and triglyceride concentrations at baseline and yearly during follow-up using standard methods. Laboratory staff were blinded to the intervention group.

Table 1: Baseline characteristics of the study participants

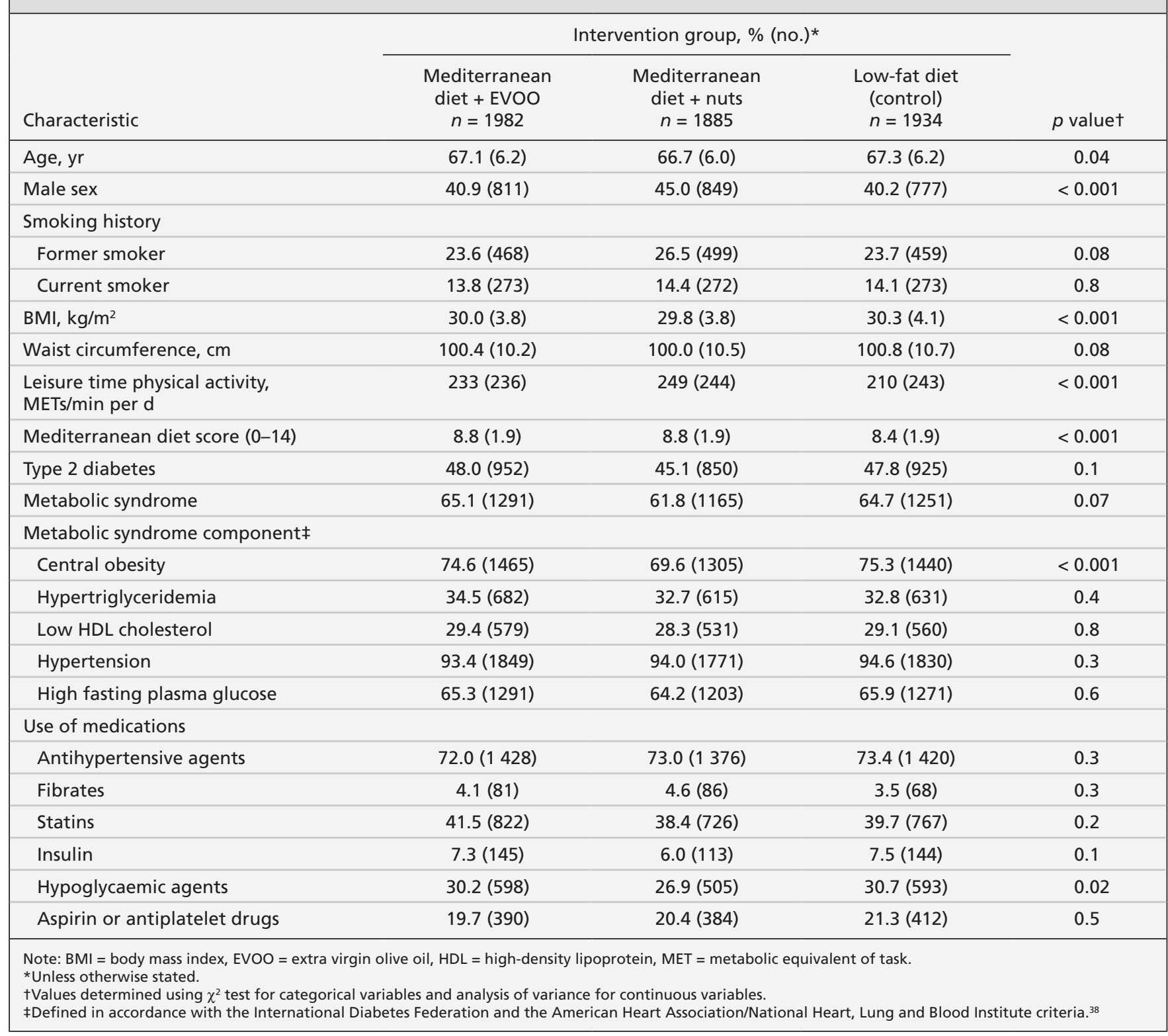




\section{Statistical analyses}

Assuming an expected incidence of metabolic syndrome of $21 \%$ and a hazard ratio (HR) of 0.7 for the comparison of the intervention groups with the control group, the statistical power for our analyses is $83 \%$. Assuming an expected reversion rate of metabolic syndrome of $7.5 \%$ and a HR of 1.7 for the comparison of the intervention groups with the control group, the statistical power for our analyses is $92 \%$.

We used the Bonferroni method to test multiple comparisons of the 5 components of metabolic syndrome between intervention groups at the end of follow-up. We used generalized estimating equations to assess changes in the incidence of metabolic syndrome between intervention groups during follow-up. We fitted Cox regression models to determine HRs and $95 \%$ confidence intervals (CIs) for incidence or reversion by intervention group.

For our primary analyses of incidence or reversion, the time variable was the interval between randomization and either the date of incidence or reversion, the date of the last follow-up visit, the date of death or the date on which the participant was lost to follow-up, whichever occurred first.

All $p$ values are 2-tailed with a signifance level of less than 0.05 . We performed statistical analyses using SPSS version 19.0 and STATA version 12.0.

\section{Results}

Of the 7447 participants in the PREDIMED trial, biochemical determinations were available for $5801(77.9 \%)$ (Appendix 1, available at www.cmaj .ca/lookup/suppl/doi:10.1503/cmaj.140764/-/DC1). We found no differences in the main characteristics of participants betw een the total cohort of participants and those included in our analysis (data not shown).

Among participants with or without metabolic syndrome at baseline (Appendices 2 and 3, available at www.cmaj.ca/lookup/suppl/doi:10.1503 /cmaj.140764/-/DC1), the median Mediterranean diet score (as determined using the 14-item questionnaire) throughout follow-up was significantly higher among participants allocated to the Mediterranean diet groups compared with those in the control group.

Throughout follow-up, consumption of nuts and extra-virgin olive oil were significantly higher among participants allocated to the Mediterranean diets supplemented with nuts or olive oil, respec-

Table 2: Prevalence of metabolic syndrome and its component conditions at baseline and final follow-up

\begin{tabular}{|c|c|c|c|c|}
\hline \multirow[b]{2}{*}{ Condition } & \multicolumn{3}{|c|}{ Intervention, \% (no.) } & \multirow[b]{2}{*}{$p$ value* } \\
\hline & $\begin{array}{c}\text { Mediterranean } \\
\text { diet + EVOO }\end{array}$ & $\begin{array}{l}\text { Mediterranean } \\
\text { diet + nuts }\end{array}$ & $\begin{array}{l}\text { Low-fat diet } \\
\text { (control) }\end{array}$ & \\
\hline Metabolic syndrome & $n=1982$ & $n=1885$ & $n=1934$ & \\
\hline At baseline & $65.1(1291)$ & $61.8(1165)$ & $64.7(1251)$ & 0.07 \\
\hline At final follow-up & $66.6(1320)$ & $64.9(1223)$ & $68.6(1326)$ & 0.05 \\
\hline At baseline & $74.4(1474)$ & 69.5 (1319) & $75.3(1451)$ & $<0.001$ \\
\hline At final follow-up & $74.1(1467)$ & 70.9 (1345) & $75.0(1445)$ & 0.005 \\
\hline Hypertriglyceridemia & $n=1994$ & $n=1891$ & $n=1946$ & \\
\hline At baseline & $34.3(683)$ & $32.5(615)$ & $32.5(634)$ & 0.4 \\
\hline At final follow-up & $35.0(694)$ & $34.8(656)$ & $34.3(668)$ & 0.9 \\
\hline Hypertension & $n=2032$ & $n=1934$ & $n=1990$ & \\
\hline At baseline & 93.5 (1899) & $93.8(1814)$ & $94.7(1884)$ & 0.3 \\
\hline At final follow-up & $95.4(1938)$ & $94.8(1833)$ & 95.4 (1899) & 0.6 \\
\hline High fasting plasma glucose & $n=2010$ & $n=1896$ & $n=1966$ & \\
\hline At baseline & $65.6(1319)$ & $64.5(1223)$ & $66.3(1304)$ & 0.5 \\
\hline At final follow-up & $68.9(1385)$ & $68.4(1296)$ & $71.9(1414)$ & 0.03 \\
\hline
\end{tabular}


tively (Appendix 4, available at www.cmaj.ca /lookup/suppl/doi:10.1503/cmaj.140764/-/DC1). Changes in body weight and physical activity were small and did not differ significantly between groups (Appendix 5, available at www.cmaj.ca /lookup/suppl/doi:10.1503/cmaj.140764/-(DC1).

Of the 5801 participants included in our analysis (Table 1), 63.9\% $(n=3707)$ met the criteria for metabolic syndrome at baseline. The prevalence of central obesity and high fasting plasma glucose were significantly higher in the control group at the end of follow-up (Table 2) than in the Mediterranean diet groups. We saw a significant difference in central obesity between Mediterranean diet groups at the end of follow-up (Bonferroni adjusted $p=0.025$ ). After a median follow-up of 4.8 years, we found a significantly smaller increase in the prevalence of metabolic syndrome among participants assigned to the Mediterranean diet supplemented with extra-virgin olive oil than among participants in the control group ( $p=0.013$ ) (Figure 1).

We assessed incidence of metabolic syndrome for 2094 participants who did not have the condition at baseline (691 in the olive oil supplementation group, 720 in the nut supplementation group and 683 in the control group). Data were missing for some of the covariables needed to assess incidence for 175 participants (Appendix 6, available at www.cmaj.ca/lookup /suppl/doi:10.1503/cmaj.140764/-/DC1). Thus, our analysis on incidence included data from 1919 participants.

Over a median follow-up of $3.2 \mathrm{yr}$ (maximum $7 \mathrm{yr}$ ), we found no between-group differences in the cumulative incidence of metabolic syndrome or its components (Appendix 7, available at www. cmaj.ca/lookup/suppl/doi:10.1503/cmaj.140764 /-/DC1).

The risk of metabolic syndrome incidence (Table 3) did not differ significantly between the Mediterranean diet groups and the control group (control v. olive oil HR 1.10, 95\% CI 0.94-1.30, $p=0.231$; control v. nuts HR $1.08,95 \%$ CI $0.92-1.27, p=0.322$ ). In addition, the risk of each component of metabolic syndrome did not show significant between-group differences (Appendix 8, available at www.cmaj.ca/lookup /suppl/doi:10.1503/cmaj.140764/-/DC1).

To assess reversion, we included only those participants who had metabolic syndrome at baseline ( $n=3707)$; however, data were missing for 315 participants. Thus, we included data from 3392 participants in our analyses. During a median follow-up of 4.8 years, reversion occurred in 958 (28.2\%) participants (Appendix 9, available at www.cmaj.ca/lookup /suppl/doi:10.1503/cmaj.140764/-/DC1). Compared with the control diet, both Mediterranean diets were significantly more likely to revert metabolic syndrome (control v. olive oil HR 1.35, $95 \%$ CI 1.15-1.58, $p<0.001$; control v. nuts HR

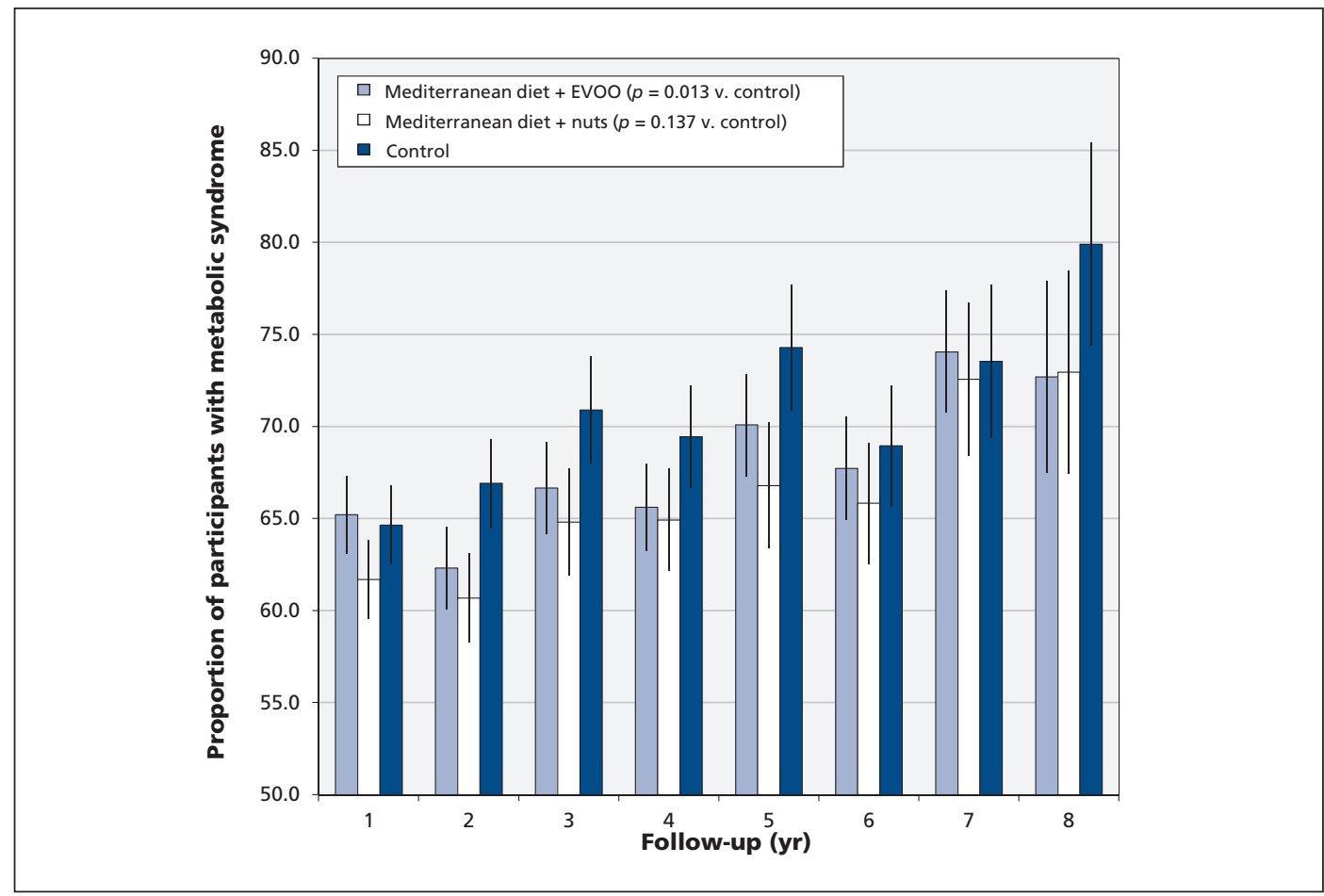

Figure 1: Prevalence of metabolic syndrome during follow-up. Error bars denote $95 \%$ confidence intervals. The changes were assessed with generalized estimating equations, and the $p$ values shown are for the overall trend. Note: EVOO = extra-virgin olive oil. 
$1.28,95 \%$ CI $1.08-1.51, p<0.001)$. The cumulative reversion rates for metabolic syndrome, central obesity and high fasting plasma glucose differed significantly among the 3 groups. Reversion was higher in both Mediterranean diet groups compared with the control group (Table 3, Appendix 10, available at www.cmaj.ca/lookup /suppl/doi:10.1503/cmaj.140764/-/DC1).

Participants assigned to the Mediterranean diets were significantly more likely to no longer meet the criterion of central obesity compared with those in the control group (both $p<0.001$ ), even after adjustment for confounders (Appendix 11, available at www.cmaj.ca/lookup/suppl/doi:10.1503 /cmaj.140764/-/DC1). Compared with the control group, only the participants in the group supplemented with extra-virgin olive oil were more likely to no longer meet the criterion of high fasting plasma glucose $(p=0.02)$.

\section{Discussion}

In this large, multicentre, randomized controlled trial involving people with high cardiovascular risk, a Mediterranean diet supplemented with extra-virgin olive oil was associated with a smaller increase in the prevalence of metabolic syndrome compared with advice on following a low-fat diet. However, we found no beneficial effect of a Mediterranean diet on incidence of new-onset metabolic syndrome. Thus, the smaller increase in prevalence was likely due to reversion. Because there were no between-group differences in weight loss or energy expenditure, the change is likely attributable to the difference in dietary patterns.

Our results are not consistent with those of observational studies ${ }^{24}$ that have shown a beneficial effect of a Mediterranean diet on the incidence of metabolic syndrome. However, our results are consistent with those of Esposito and colleagues ${ }^{33}$ who found beneficial effects on metabolic syndrome and its components with an energy-restricted Mediterranean diet in a short clinical trial. Contrary to our study, their results could have been due to energy restriction leading to substantial weight loss. ${ }^{33}$

Similar to the previous PREDIMED report, ${ }^{35}$ we found a beneficial effect of a Mediterranean diet on reversion of metabolic syndrome, but not on the incidence of the condition. However, we did see a net beneficial effect on prevalence as a result of reversion.

We found the Mediterranean diet supplemented with extra-virgin olive-oil to have the most beneficial effect on central obesity and hyperglycemia. These results concur with those of cross-sectional ${ }^{26,41,42}$ and prospective epidemiologic studies ${ }^{24,30,32}$ that showed an inverse association between adherence to a Mediterranean diet and central obesity.

We can speculate that a Mediterranean diet, particularly one supplemented with extra-virgin olive oil (which has anti-inflammatory properties), could exert positive effects on fat redistribution. In a short-term experimental crossover study involving participants with obesity and insulin resistance, an isocaloric Mediterranean diet rich in extra-virgin olive oil prevented accumulation of central body fat compared with a low-fat diet, without affecting body weight. ${ }^{43} \mathrm{In}$ addition, there is evidence that patients with type 2 diabetes involved in weight maintenance programs tend to have a disproportionate loss of lower body versus upper body fat compared with patients given a diet rich in monounsaturated fatty acids. ${ }^{44}$

The protective effect on the hyperglycemia component of the metabolic syndrome that we saw with olive oil supplementation is also consistent with the efficacy of dietary monounsatu-

Table 3: Risk of metabolic syndrome* incidence and reversion by intervention

\begin{tabular}{|c|c|c|c|c|}
\hline \multirow[b]{2}{*}{ Model } & \multicolumn{2}{|c|}{$\begin{array}{c}\text { Incidence } \\
\mathrm{HR}(95 \% \mathrm{Cl}) \dagger\end{array}$} & \multicolumn{2}{|c|}{$\begin{array}{c}\text { Reversion } \\
\text { HR }(95 \% \mathrm{Cl}) \dagger\end{array}$} \\
\hline & $\begin{array}{l}\text { Mediterranean } \\
\text { diet + EVOO v. control } \\
\quad n=663\end{array}$ & $\begin{array}{l}\text { Mediterranean } \\
\text { diet }+ \text { nuts v. control } \\
\quad n=662\end{array}$ & $\begin{array}{l}\text { Mediterranean } \\
\text { diet + EVOO v. control } \\
\quad n=1236\end{array}$ & $\begin{array}{l}\text { Mediterranean } \\
\text { diet }+ \text { nuts v. control } \\
\quad n=1062\end{array}$ \\
\hline Crude model & $1.04(0.89-1.21)$ & $1.04(0.88-1.19)$ & $1.42(1.21-1.66)$ & $1.42(1.20-1.67)$ \\
\hline $\begin{array}{l}\text { Age-, sex- and centre-adjusted } \\
\text { model }\end{array}$ & $1.03(0.88-1.21)$ & $1.01(0.86-1.19)$ & $1.42(1.21-1.67)$ & $1.38(1.17-1.63)$ \\
\hline Multivariable adjusted modelł & $1.10(0.94-1.30)$ & $1.08(0.92-1.27)$ & $1.35(1.15-1.58)$ & $1.28(1.08-1.51)$ \\
\hline \multicolumn{5}{|c|}{$\begin{array}{l}\text { Note: } \mathrm{Cl}=\text { confidence interval, } \mathrm{EVOO}=\text { extra-virgin olive oil, } \mathrm{HR}=\text { hazard ratio. } \\
\text { *Defined in accordance with the International Diabetes Federation and the American Heart Association/National Heart, Lung, and Blood Institute criteria. }{ }^{38} \\
\text { tCox regression model. } \\
\text { †Adjusted for sex, age, Mediterranean diet score, energy intake, body mass index, physical activity, smoking and antidiabetic drugs other than insulin. All models } \\
\text { were stratified by recruitment centre. }\end{array}$} \\
\hline
\end{tabular}


rated fatty acids for reducing cardiovascular risk factors related to metabolic syndrome ${ }^{45}$ and the risk of insulin resistance and diabetes. ${ }^{21}$ Several controlled interventions have shown that diets rich in monounsaturated fatty acids improve insulin sensitivity compared with those high in saturated fatty acids. ${ }^{43,46}$

The Mediterranean diet includes components beyond monounsaturated fatty acids that have been reported to improve inflammation, oxidative stress, insulin resistance and secretion pathogenic factors in obesity, diabetes and metabolic syndrome. For example, many fruits, vegetables and seeds contain minerals, polyphenols and other phytochemicals that combat oxidative stress, inflammation and insulin resistance. ${ }^{47,48}$ Extra-virgin olive oil and nuts show potent anti-inflammatory ${ }^{49}$ and antioxidant effects, and both of the PREDIMED Mediterranean diets have shown these effects. ${ }^{50,51}$ Many components of the Mediterranean diet are likely to be beneficial in terms of glucose metabolism, reducing the risk of diabetes. ${ }^{21}$ However, the recognized protective effect of the Mediterranean diet was not enough to prevent metabolic syndrome in our study population.

\section{Limitations}

Incidence and reversion of metabolic syndrome were secondary end-points of the PREDIMED trial, making our analyses exploratory in nature. Because our sample comprised older participants at high risk of cardiovascular disease, our results cannot be generalized to the general population. Complete data were not available for analysis for some of the participants; we had greater losses during follow-up in the control group, but participants who dropped out had a worse cardiovascular risk profile at baseline than participants who remained in the study, suggesting a bias toward benefit in the control group.

\section{Conclusion}

Mediterranean diets supplemented with olive oil or nuts were not associated with a reduced incidence of metabolic syndrome compared with a low-fat diet; however, both diets were associated with a significant rate of reversion of metabolic syndrome. Such diets may be useful in reducing central obesity and hyperglycemia in patients with high risk of cardiovascular disease.

\section{References}

1. Isomaa B, Almgren P, Tuomi T, et al. Cardiovascular morbidity and mortality associated with the metabolic syndrome. Diabetes Care 2001;24:683-9.

2. Schmidt C, Bergström GML. The metabolic syndrome predicts cardiovascular events: results of a 13-year follow-up in initially healthy 58-year-old men. Metab Syndr Relat Disord 2012;10: 394-9.
3. Mozaffarian D, Kamineni A, Prineas RJ, et al. Metabolic syndrome and mortality in older adults: the Cardiovascular Health Study. Arch Intern Med 2008;168:969-78.

4. Mottillo S, Filion KB, Genest J, et al. The metabolic syndrome and cardiovascular risk a systematic review and meta-analysis. $J$ Am Coll Cardiol 2010;56:1113-32.

5. Sun D-L, Wang J-H, Jiang B, et al. Metabolic syndrome vs, its components for prediction of cardiovascular mortality: a cohort study in Chinese elderly adults. J Geriatr Cardiol 2012;9:123-9.

6. Athyros VG, Ganotakis ES, Elisaf M, et al. The prevalence of the metabolic syndrome using the National Cholesterol Educational Program and International Diabetes Federation definitions. Curr Med Res Opin 2005;21:1157-9.

7. Ford ES, Li C, Zhao G. Prevalence and correlates of metabolic syndrome based on a harmonious definition among adults in the US. J Diabetes 2010;2:180-93.

8. Beltrán-Sánchez H, Harhay MO, Harhay MM, et al. Prevalence and trends of metabolic syndrome in the adult U.S. population, 1999-2010. J Am Coll Cardiol 2013;62:697-703.

9. Riediger ND, Clara I. Prevalence of metabolic syndrome in the Canadian adult population. CMAJ 2011;183:E1127-34.

10. Yamaoka K, Tango T. Effects of lifestyle modification on metabolic syndrome: a systematic review and meta-analysis. BMC Med 2012; 10:138.

11. Earnest CP, Johannsen NM, Swift DL, et al. Dose effect of cardiorespiratory exercise on metabolic syndrome in postmenopausal women. Am J Cardiol 2013;111:1805-11.

12. Azadbakht L, Mirmiran P, Esmaillzadeh A, et al. Beneficial effects of a dietary approaches to stop hypertension eating plan on features of the metabolic syndrome. Diabetes Care 2005;28:2823-31.

13. Akbaraly TN, Singh-Manoux A, Tabak AG, et al. Overall diet history and reversibility of the metabolic syndrome over 5 years: the Whitehall II prospective cohort study. Diabetes Care 2010;33: 2339-41.

14. Case CC, Jones PH, Nelson K, et al. Impact of weight loss on the metabolic syndrome. Diabetes Obes Metab 2002;4:407-14.

15. Lofgren IE, Herron KL, West KL, et al. Weight loss favorably modifies anthropometrics and reverses the metabolic syndrome in premenopausal women. J Am Coll Nutr 2005;24:486-93.

16. de la Iglesia R, Lopez-Legarrea P, Abete I, et al. A new dietary strategy for long-term treatment of the metabolic syndrome is compared with the American Heart Association (AHA) guidelines: the MEtabolic Syndrome REduction in NAvarra (RESMENA) project. Br J Nutr 2014;111:643-52.

17. Estruch R, Ros E, Salas-Salvadó J, et al. Primary prevention of cardiovascular disease with a Mediterranean diet. $N$ Engl J Med 2013;368:1279-90.

18. Estruch R, Martínez-González MA, Corella D, et al. Effects of a Mediterranean-style diet on cardiovascular risk factors: a randomized trial. Ann Intern Med 2006;145:1-11.

19. Salas-Salvadó J, Bulló M, Babio N, et al. Reduction in the incidence of type 2 diabetes with the Mediterranean diet: results of the PREDIMED-Reus nutrition intervention randomized trial. Diabetes Care 2011;34:14-9.

20. Rossi M, Turati F, Lagiou P, et al. Mediterranean diet and glycaemic load in relation to incidence of type 2 diabetes: results from the Greek cohort of the population-based European Prospective Investigation into Cancer and Nutrition (EPIC). Diabetologia 2013:56:2405-13.

21. Salas-Salvadó J, Martinez-González MÁ, Bulló M, et al. The role of diet in the prevention of type 2 diabetes. Nutr Metab Cardiovasc Dis 2011;21(Suppl 2):B32-48

22. Estruch R. Anti-inflammatory effects of the Mediterranean diet: the experience of the PREDIMED study. Proc Nutr Soc 2010; 69:333-40.

23. Núñez-Córdoba JM, Valencia-Serrano F, Toledo E, et al. The Mediterranean diet and incidence of hypertension: the Seguimiento Universidad de Navarra (SUN) Study. Am J Epidemiol 2009;169:339-46.

24. Kastorini C-M, Milionis HJ, Esposito K, et al. The effect of Mediterranean diet on metabolic syndrome and its components: a meta-analysis of 50 studies and 534,906 individuals. J Am Coll Cardiol 2011;57:1299-313.

25. Panagiotakos DB, Pitsavos C, Chrysohoou C, et al. Impact of lifestyle habits on the prevalence of the metabolic syndrome among Greek adults from the ATTICA study. Am Heart $J$ 2004;147:106-12.

26. Babio N, Bulló M, Basora J, et al. Adherence to the Mediterranean diet and risk of metabolic syndrome and its components. Nutr Metab Cardiovasc Dis 2009;19:563-70.

27. Doupis J, Dimosthenopoulos C, Diamanti K, et al. Metabolic syndrome and Mediterranean dietary pattern in a sample of young, male, Greek navy recruits. Nutr Metab Cardiovasc Dis 2009;19:e7-8. 
28. Paletas K, Athanasiadou E, Sarigianni M, et al. The protective role of the Mediterranean diet on the prevalence of metabolic syndrome in a population of Greek obese subjects. J Am Coll Nutr 2010;29:41-5.

29. Viscogliosi G, Cipriani E, Liguori ML, et al. Mediterranean dietary pattern adherence: associations with prediabetes, metabolic syndrome, and related microinflammation. Metab Syndr Relat Disord 2013;11:210-6.

30. Tortosa A, Bes-Rastrollo M, Sanchez-Villegas A, et al. Mediterranean diet inversely associated with the incidence of metabolic syndrome: the SUN prospective cohort. Diabetes Care 2007;30:2957-9.

31. Rumawas ME, Meigs JB, Dwyer JT, et al. Mediterranean-style dietary pattern, reduced risk of metabolic syndrome traits, and incidence in the Framingham Offspring Cohort. Am J Clin Nutr 2009;90:1608-14. 32. Kesse-Guyot E, Ahluwalia N, Lassale C, et al. Adherence to Mediterranean diet reduces the risk of metabolic syndrome: a 6-year prospective study. Nutr Metab Cardiovasc Dis 2013;23:677-83.

33. Esposito K, Marfella R, Ciotola M, et al. Effect of a Mediterranean-style diet on endothelial dysfunction and markers of vascular inflammation in the metabolic syndrome: a randomized trial. JAMA 2004;292:1440-6.

34. Richard C, Couture P, Desroches S, et al. Effect of the Mediterranean diet with and without weight loss on cardiovascular risk factors in men with the metabolic syndrome. Nutr Metab Cardiovasc Dis 2011;21:628-35.

35. Salas-Salvadó J, Fernández-Ballart J, Ros E, et al. Effect of a Mediterranean diet supplemented with nuts on metabolic syndrome status: one-year results of the PREDIMED randomized trial. Arch Intern Med 2008;168:2449-58.

36. Martínez-González MÁ, Corella D, Salas-Salvadó J, et al Cohort profile: design and methods of the PREDIMED study. Int J Epidemiol 2012;41:377-85.

37. Schröder H, Fitó M, Estruch R, et al. A short screener is valid for assessing Mediterranean diet adherence among older Spanish men and women. J Nutr 2011;141:1140-5.

38. Alberti KGMM, Eckel RH, Grundy SM, et al. Harmonizing the metabolic syndrome: a joint interim statement of the International Diabetes Federation Task Force on Epidemiology and Prevention; National Heart, Lung, and Blood Institute; American Heart Association; World Heart Federation; International. Circulation 2009;120:1640-5.

39. Fernández-Ballart JD, Piñol JL, Zazpe I, et al. Relative validity of a semi-quantitative food-frequency questionnaire in an elderly Mediterranean population of Spain. Br J Nutr 2010;103:1808-16.

40. Elosua R, Marrugat J, Molina L, et al. Validation of the Minnesota Leisure Time Physical Activity Questionnaire in Spanish men. The MARATHOM Investigators. Am J Epidemiol 1994; 139:1197-209.

41. Romaguera D, Norat T, Mouw T, et al. Adherence to the Mediterranean diet is associated with lower abdominal adiposity in European men and women. J Nutr 2009;139:1728-37.

42. Martínez-González MA, García-Arellano A, Toledo E, et al. A 14-item Mediterranean diet assessment tool and obesity indexes among high-risk subjects: the PREDIMED trial. PLoS ONE 2012;7:e43134.

43. Paniagua JA, Gallego de la Sacristana A, Romero I, et al Monounsaturated fat-rich diet prevents central body fat distribution and decreases postprandial adiponectin expression induced by a carbohydrate-rich diet in insulin-resistant subjects. Diabetes Care 2007;30:1717-23.

44. Walker KZ, O'Dea K, Johnson L, et al. Body fat distribution and non-insulin-dependent diabetes: comparison of a fiberrich, high-carbohydrate, low-fat $(23 \%)$ diet and a 35\% fat diet high in monounsaturated fat. Am J Clin Nutr 1996;63:254-60.

45. Gillingham LG, Harris-Janz S, Jones PJH. Dietary monounsaturated fatty acids are protective against metabolic syndrome and cardiovascular disease risk factors. Lipids 2011;46:209-28.

46. Vessby B, Uusitupa M, Hermansen K, et al. Substituting dietary saturated for monounsaturated fat impairs insulin sensitivity in healthy men and women: The KANWU Study. Diabetologia 2001;44:312-9

47. Calder PC, Ahluwalia N, Brouns F, et al. Dietary factors and low-grade inflammation in relation to overweight and obesity. Br J Nutr 2011;106(Suppl3):S5-78

48. Esfahani A, Wong JMW, Truan J, et al. Health effects of mixed fruit and vegetable concentrates: a systematic review of the clinical interventions. $J$ Am Coll Nutr 2011;30:285-94.

49. Urpi-Sarda M, Casas R, Chiva-Blanch G, et al. Virgin olive oil and nuts as key foods of the Mediterranean diet effects on inflammatory biomakers related to atherosclerosis. Pharmacol Res 2012;65:577-83

50. Fitó M, Guxens M, Corella D, et al. Effect of a traditiona
Mediterranean diet on lipoprotein oxidation: a randomized controlled trial. Arch Intern Med 2007;167:1195-203

51. Mena M-P, Sacanella E, Vazquez-Agell M, et al. Inhibition of circulating immune cell activation: a molecular antiinflammatory effect of the Mediterranean diet. Am J Clin Nutr 2009;89: 248-56.

Competing interests: Ramón Estruch serves on the board of and has received lecture fees from the Research Foundation on Wine and Nutrition (FIVIN); he serves on the boards of the Beer and Health Foundation and the European Foundation for Alcohol Research; he has received lecture fees from Cerveceros de España and Sanofi-Aventis and grant support from Novartis. Emilio Ros serves on the board of and has received travel and grant support from the California Walnut Commission; he serves on the board of the Flora Foundation (Unilever); he serves on the board of and has received lecture fees from Roche; he serves on the board of and has received grant support from Amgen; he has received consulting fees from Damm and Abbott Laboratories; he has received consulting fees, lecture fees and grant support from Merck; he has received lecture fees from Danone, Pace, Astra Zeneca and Rottapharm; he has received lecture fees, grant support and payment for the development of educational presentations from Ferrer; he has received payment for the development of educational presentations from Recordati; and he has received grant support from Sanofi-Aventis, Takeda, Daiichi Sankyo, Nutrexpa, Feiraco, Unilever, and Karo Bio. Fernando Arós has received payment for the development of educational presentations from Menarini and Astra Zeneca. Rosa Lamuela-Raventos serves on the board of and has received lecture fees from FIVIN; has received lecture fees from Cerveceros de España; and has received lecture fees and travel support from PepsiCo. Lluís Serra-Majem serves on the boards of the Mediterranean Diet Foundation and the Beer and Health Foundation; he is a member of the scientific advisory board and has received consulting fees and grant support from the European Hyratation Institute; he has received lecture fees from the International Nut Council; he has received travel support for conferences from Nestlé. Xavier Pintó serves on the board of and has received grant support from the Residual Risk Reduction Initiative Foundation; he serves on the board of Omegafort; he serves on the board of and has received payment for the development of educational presentations and grant support from Ferrer; he has received consulting fees from Abbott Laboratories; he has received lecture fees and grant support from Merck and Roche; he has received lecture fees from Danone and Esteve; he has received payment for the development of educational presentations from Menarini; and he has received grant support from Sanofi-Aventis, Kowa, Unilever, Boehringer Ingelheim and Karo Bio. Jordi Salas-Salvadó serves on the board of and has received grant support from the International Nut and Dried Fruit Council; he has received consulting fees from Danone; and he has received grant support from Eroski and Nestlé. No other competing interests were declared.

Affiliations: Human Nutrition Unit (Babio, Bulló, Basora, Salas-Salvadó), Faculty of Medicine and Health Sciences, Biochemistry Biotechnology Department, Universitat Rovira i Virgili, and Hospital Universitari de Sant Joan de Reus, IISPV, Reus, Spain; Centro de Investigación Biomédica en Red Fisiopatología de la Obesidad y Nutrición (CIBERobn) (Babio, Toledo, Estruch, Martínez-González, Castañer, Bulló, Corella, Arós, Gómez-Gracia, Ruiz-Gutiérrez, Fiol, Lapetra, Lamuela-Raventos, Serra-Majem, Pintó, Basora, Sorlí, SalasSalvadó), Institute of Health Carlos III, Madrid, Spain; Department of Preventive Medicine and Public Health (Toledo, Martínez-González), University of Navarra, Pamplona, Spain; Department of Internal Medicine (Estruch), Institut d'Investigacions Biomèdiques August Pi Sunyer (IDIBAPS), Hospital Clínic, University of Barcelona, Barcelona, Spain; Lipid Clinic (Ros), Endocrinology and Nutrition Service, IDIBAPS, Hospital Clinic, University of Barcelona, Barcelona, Spain; Cardiovascular Risk and Nutrition 
Research Group (Castañer), Institut Hospital del Mar d'Investigacions Mèdiques (IMIM), Barcelona Biomedical Research Park, Barcelona, Spain; Department of Preventive Medicine (Corella, Sorlí), University of Valencia, València, Spain; Department of Cardiology (Arós), University Hospital Txagorritxu, Vitoria, Spain; Department of Preventive Medicine (Gómez-Gracia), University of Malaga, Malaga, Spain; Instituto de la Grasa (Ruiz-Gutiérrez), Consejo Superior de Investigaciones Cientificas, Seville; Instituto de Investigación Sanitaria de Palma (Fiol), Hospital Universitario Son Espases, Mallorca; Department of Family Medicine (Lapetra), Primary Care Division of Seville, San Pablo Health Center, Seville; Department of Nutrition and Food Science (Lamuela-Raventos), School of Pharmacy, Xarxa de Referència en Tecnologia dels Aliments, Instituto de Investigación en Nutrición y Seguridad Alimentaria, University of Barcelona, Barcelona, Spain; Department of Clinical Sciences (Serra-Majem), University of Las Palmas de Gran Canaria, Las Palmas, Spain; Lipids and Vascular Risk Unit (Pintó), Internal Medicine, Hospital Universitario de Bellvitge, Hospitalet de Llobregat, Barcelona, Spain; Primary Care Division (Basora), Catalan Institute of Health, Institut Universitari d'Investigació en Atenció Primària Jordi Gol, Tarragona-Reus, Spain.

Contributors: Nancy Babio and Jordi Salas-Salvadó had full access to all the data in the study and take responsibility for the integrity of the data and the accuracy of the data analysis. Study concept and design: Emilio Ros, Miguel MartínezGonzález, Dolores Corella, Fernando Arós, Enrique GómezGracia, Valentina Ruiz-Gutiérrez, Miquel Fiol, José Lapetra, Rosa M. Lamuela-Raventos, Lluís Serra-Majem, Xavier Pintó and Jordi Salas-Salvadó. Analysis and interpretation of data: Nancy Babio, Estefanía Toledo, Miguel Martínez-González and Jordi Salas-Salvadó. Drafting of the manuscript: Nancy Babio and Jordi Salas-Salvadó. Critical revision of the manuscript for important intellectual content: All the authors. Statistical analysis: Nancy Babio, Estefanía Toledo.

The PREDIMED Study Investigators: C. Viñas, R. Casas, J.M. Baena, M. Oller, J. Amat, I. Duaso, Y. García, C. Iglesias and J. Benavent (Hospital Clinic, Institut d'Investigacions Biomèdiques August Pi i Sunyer, Barcelona, Spain); A. Sánchez-Tainta, E. Toledo, P. Buil-Cosiales, M. Serrano-Martínez, J. Díez-Espino, A. García-Arellano, I. Zazpe and J. BasterraGortari (University of Navarra, Primary Care Division Centres,
Pamplona, Spain); R. González, C. Molina, M. Sorli, J. GarcíaRoselló, J., Fernández-Ballart, A. Castro, R. Sagarra, R.Pedret, F. París and M. Llauradó (University Rovira i Virgili, Reus, Spain); S. Tello, J. Vila, M. Fitó and H. Schröder (Institute de Recerca Hospital del Mar, Barcelona, Spain); F. Aros del Hierro and J. Algorta (University Hospital of Alava, Vitoria, Spain); R. Benítez Pont, M. Bianchi Alba, J.Fernández-Crehuet Navajas and E. Gómez-Gracia (University of Málaga, Málaga, Spain); F.J. García, P. Roman, J.M. Santos and J. Lapetra (Department of Family Medicine, Primary Care Division of Sevilla, Sevilla, Spain); J. Álvarez-Pérez, E. Díez Benítez, I. Bautista Castaño and A. Sánchez-Villegas (University of Las Palmas de Gran Canaria, Las Palmas, Spain).

Funding: CIBERobn is an initiative of ISCIII, Spain. Supported by the official funding agency for biomedical research of the Spanish government, Instituto de Salud Carlos III (ISCIII), through grants provided to research networks specifically developed for the trial (RTIC G03/140, to Ramón Estruch; RTIC RD 06/0045, to Miguel Martínez-González and through Centro de Investigación Biomédica en Red de Fisiopatología de la Obesidad y Nutrición [CIBERobn]), and by grants from Centro Nacional de Investigaciones Cardiovasculares (CNIC 06/2007), Fondo de Investigación Sanitaria-Fondo Europeo de Desarrollo Regional (PI04-2239, PI 05/2584, CP06/00100, PI07/0240, PI07/1138, PI07/0954, PI 07/0473, PI10/01407, PI10/02658, PI11/01647, and P11/02505; PI13/00462), Ministerio de Ciencia e Innovación (AGL-2009-13906-C02 and AGL2010-22319-C03), Fundación Mapfre 2010, Consejería de Salud de la Junta de Andalucía (PI0105/2007), Public Health Division of the Department of Health of the Autonomous Government of Catalonia, Generalitat Valenciana (ACOMP06109, GVACOMP2010-181, GVACOMP2011-151, CS2010-AP-111, and CS2011-AP-042), and Regional Government of Navarra (P27/2011). None of the funding sources played a role in the design, collection, analysis or interpretation of the data or in the decision to submit the manuscript for publication.

Data sharing: The PREDIMED trial data are not available for sharing.

Acknowledgements: The authors thank the participants for their enthusiastic collaboration, the PREDIMED personnel for their excellent assistance and the personnel of all affiliated primary care centres. 